\title{
The Need for IT Education for Business Managers for the Success of the Business
}

\author{
Tesfahun Tegegn \\ Wolaita Sodo University
}

\begin{abstract}
Whatever decision managers make with regards to making the business organization competent in the market place to be successful, it should be harmonized with the information technology tools because in this digital era the market works with computers, internet and so forth. Therefore to make the organization competent, to respond to new development, to create highly satisfying customer service managers should make themselves educated with IT and should be able to cope up with the changing technology so as to make the business success. Unless otherwise being unable to cope up with these technologies will not only affect the business success but also it also have effect in its existence in the market. As IT solutions continue to increase the productivity, efficiency and effectiveness of business operations and communication, business will continue to rely on Information Technology for success whenever the managers are either IT educated or get assistant from IT specialist.
\end{abstract}

DOI: $10.7176 / \mathrm{IKM} / 9-4-03$

Publication date: April $30^{\text {th }} 2019$

\section{Introduction}

Innovation is the great way to success in this digital age. The path of innovation in business means doing something different, smarter or better that will make a positive difference in terms of value, quality or productivity by using emerging or proved technologies of the world. The technology which has already proved itself in last two decades is of course the information technology (IT). It has dramatically changed the lives of the individuals and organizations. Currently online shopping, digital marketing, social networking, digital communication and cloud computing etc are the best examples of change which came through the wave of information technology. This day's accurate business planning, effective marketing, global sales, systematic management, real time monitoring, instant customer support and long term business growth cannot be achieved at the optimum level without IT.

Doing business in this digital era has changed the way how managers make decision to make the business profitable. It is no longer based on face to face or using a broker but also managers should also look for information from the internet to get to know the targeted customers behavior, where they are located, what type of product or service they like, who will be the competitor, what are the strength and weakness of the competitor and so forth. Across all sizes of organizations there is generally clear evidence of ICT (Information and Communication Technology), be it through, for example, the telephone, mobile/cellular phone, network switch/router, PC, laptop or tablet computer. Invariably, these and many other devices are considered integral to a firm, as they assist employees to, among other things:

Making promotion available to customers through net

Communicate with customers, partners and each other

Repair and transmit documents and files, and

Browse online and conduct a wide range of electronic transactions.

Selling products and buying materials through internet

Make trade agreement by teleconferencing

Wiring money, transferring money and withdrawal through ATM

When managers in a given organization are well equipped with information technologies know how then this could be one factor that could help to make better decision so as to make the business successful. However, although such technology is considered integral to an organization, frequently they are not harnessed to their fullest potential to improve its performance. Below ways in which technology could be better applied and then managers can make the following difference in the organization.

\section{To improve service delivery to customers}

In today's business, business organizations could not keep doing business or sell product to customers through middleman or retailers but this days managers of the business are expected to provide the product/ service through different ICT tools so as to improve the service delivery and creating loyalty and then making profit out of the business.

From private sector to government, much can be done to improve the customer's experience, and technology can be a major contributor to that transformation. Depending on the organization and the services 
being provided, it is likely that a detailed list of improvements can be identified, but some likely to be on the list include: providing certain services online and introducing e-commerce facilities, which would, at the very least, offer customers a more convenient and efficient experience.

\section{To improve the organization's responsiveness to new developments}

Today's world is very fragile specially with regards to doing business. Any product we produce today may or may not be sold tomorrow due to the fragility of the market. This situation can have its own positive impact if the manager of a given organization is well aware of the usage of IT to make a better decision that would benefit the business organization.

Although this point might seem most relevant to complex, goods-oriented businesses that operate in highly dynamic industries, this point is as applicable to small service-oriented organizations. With regard to organizational responsiveness, ICT/technology can be a major aid in:

processing data generated from a diverse range of channels (e.g. sales, web analytics, inventory control, customer feedback, industry data, etc.), which, if handled correctly, can flag developing issues and be the impetus for important strategic decisions; and

Facilitating the implementation of the decisions that have been made, through innovative and (hopefully) cost-effective options, some of which it might be possible to build in-house.

\section{To change the basis of competition in the market}

Frequently in industry, a degree of complacency can occur when individual businesses no longer strive to distinguish themselves from their competitors. Certain equilibrium has been obtained and the businesses might be doing "okay". However, managers who have an outstanding ambitious to make their organizations grow in its market share; improve visibility; or wish to become the preferred vendor or service provider, ICT/technology can help in achieving those goals. Again, ICT/technology can be instrumental in:

Optimizing and automating certain internal processes, which can reduce delays, human error, red tape, and the complexity of certain processes so that the organization will provide the service/product to the customer on time.

Introducing operational efficiencies that can reduce costs and improve the bottom line

Implementing new measures that can ultimately add value to the customer and improve experience with the organization.

\section{To improve organization's overall performance}

Activities in the organization especially in third world countries are still being performed manually and this has created organizations not to go further meaning the small bottlenecked to get into medium and the medium to be large. So the overall performance is being affected and this could be easily solved whenever managers get their organization to be attached itself to the digital era and it also looks for the willingness of the managers to do whatever it takes to make the overall performance of the organization effective. Above all, IT has tremendous benefit with regards to supporting the organization for managers to make work so smooth.

ICT can introduce a paradigm shift in organizations with the help of managers by helping them to reevaluate, among other things, what might be possible, how they can raise the bar and perform better, and what new services and quality standards should be introduced. This point may be particularly applicable to micro, small and medium sized businesses, many of which have limited resources, and might be looking for ways to take their operations to the next level.

One way of beginning the process of getting more out of the technology that the organization currently possesses, managers should not focus on the devices themselves. Instead, the priority in the first instance should be to set the goals or desired outputs that the manager wishes to realize, and to examine and understand current processes or project cycles in order to be in a position to determine how best they can be optimized with technology to achieve the desire outcomes.

\section{To make better decision}

Speed and accuracy are at the heart of making right decision for the business. Every successful manager helps the organization to go through a comprehensive market research process which enables management to make the right decision. Market research can be done in many ways through online surveys, forums, blogs, and group discussions using World Wide Web and of course through in-person interviews as well. Currently Big data and Google Analytics are also great tools to extract useful information which can impact on decision making. These online tools not only provide real time responses from the potential audience but also ensure the accuracy of data 
by minimizing the risk of human errors so that the managers make decision best both for the organization and the customers by not compromising the targeted goal.

\section{Marketing and Business Growth}

The heart of the business success lies in its marketing which enables the management to identify its target audience first and then observe their trends and needs. The overall marketing covers public relation, advertising, promotion and sales which subsequently impact on business growth. Many types of marketing can help the manager reach potential customers. One of the IT tools mangers could use for the success of the organization is digital marketing. Digital Marketing is a modern phenomenon which will help the organization, if the managers of the business are well aware and well educated with IT or else he or she has a technical understanding of it with the help of IT assistant, promote products or services all over the world. It is a broad term which includes many concepts like blogging, discussion forum, email shot, SMS, MMS, social media marketing and Smartphone app advertisement etc. Currently web market is booming at a very fast pace because most of the entrepreneurs have understood that the long term success in business is not possible without digital presence on the internet. Millions of new websites are being added on the internet every year.

\section{Conclusion}

It is impossible to attain long term business success without leveraging the benefits of information technology in this digital age. Organizations have to bear a reasonable cost to achieve success because using an innovative approach in business strategy, employing highly trained IT professionals and making right decisions at right time are the prerequisite of business success in addition to the knowhow of the managers. As IT solutions continue and managers are well educated or get the support of the IT assistant to increase the productivity, efficiency and effectiveness of business operations and communication, business will continue to rely on Information Technology for success because IT has become the heartbeat of the organization not only to smooth the work but also to make better decision so as to benefit the company.

\section{Bibliography}

[1]Abid Afzal Butt. The Role of Information Technology in Business Success [Online]. May 14, 2015 [accessed.8.January 2017] Retrieved z: https:/www.linkedin.com/pulse/role-information-technologybusiness-success-abid-afzal-butt.

[2]Asefeh Asemi. The Role of Management Information System (MIS) and Decision Support System (DSS) for Manager's Decision Making Process [Online]. Vol. 6, No. 7; July 2011. Retrievedfile://C:/Users/dell/Downloads/8940-33616-1-PB.pdf.

[3] Harsh, Stephen B., L. J. Connor, and G. D. Schwab. Managing the Farm Business. New Jersey: Prentice-Hall, Inc., Englewood Cliffs, 1981.

[4]Nonaka, I. and H. Takeuchi. The Knowledge-Creating Company: How Japanese Companies Create the Dynamics of Innovation. NewYork: Oxford University Press, 1995. 